\title{
The dynamics of political identity and issue attitudes in adolescence and early adulthood
}

\author{
Roderik Rekker $^{\text {a, c, *, Loes Keijsers }}{ }^{\text {a, b }}$, Susan Branje ${ }^{\text {a }}$, Wim Meeus a, b \\ ${ }^{a}$ Department of Youth \& Family, Utrecht University, P.O. Box 80.140, 3508 TC, Utrecht, The Netherlands \\ b Tilburg University, The Netherlands \\ ${ }^{\mathrm{c}}$ University of Amsterdam, The Netherlands
}

\section{A R T I C L E I N F O}

Article history:

Received 21 August 2015

Received in revised form 6 May 2016

Accepted 7 February 2017

Available online 21 February 2017

\section{Keywords:}

Left-right identification

Issue attitudes

Adolescence

Early adulthood

Longitudinal

\begin{abstract}
A B S T R A C T
This cohort-sequential longitudinal study among 1302 Dutch youths examined the dynamics of political identity (e.g., Democrat or Rightist) and issue attitudes between age 12 and 30. Some theories propose that voters form an identity early in life that subsequently determines attitudes. Other theories contrarily argue that attitudes are a cause of identity. However, research on this controversy has never focused on the crucial phase of adolescence. Results revealed that youths formed an identity consistent with prior attitudes more than vice versa. Highly educated youths most often adjusted their attitudes to their identity, which explained an emerging education gap in identity-attitude consistency. Finally, findings suggested that early cultural attitudes establish an identity that may subsequently determine economic attitudes.
\end{abstract}

(C) 2017 Elsevier Ltd. All rights reserved.

\section{Introduction}

Voters commonly identify with politics in broad terms such as liberal or conservative, Democrat or Republican, and left or right. These general identifications are part of voters' identity that defines who they are and whom they belong to in society (e.g., Green et al., 2002). The theoretical debate on the nature and origins of political identity has given much attention to its relation with issue attitudes. Through identity influence, voters may adopt issue attitudes that are consistent with their identity. Through attitude influence, voters may reversely use their issue attitudes to determine their political identity. Research provides support for both mechanisms (e.g., Highton and Kam, 2011), but has generally not focused on the life phase most central to the acquisition of political identity: adolescence and early adulthood.

The present study was therefore the first to investigate if either identity influence or attitude influence best describes how voters originally acquired their political identity early in life. As such, we aimed to contribute to the theoretical understanding of political identity's nature and origins. This study was conducted in the

\footnotetext{
* Corresponding author. Department of Youth \& Family, Utrecht University, P.O. Box 80.140, 3508 TC, Utrecht, The Netherlands; Tilburg University, The Netherlands. E-mail address: r.rekker@uva.nl (R. Rekker).
}

Netherlands, where left-right identification is a far stronger element of voters' political identity than ideological or partisan identity (e.g., Van der Eijk and Niemöller, 1983). Therefore, this study focused on left-right identification as indicator of political identity in general. Specifically, we studied the dynamic reciprocal relation of left-right identification with issue attitudes on economic redistribution and the multicultural society between age 12 and 30 . These two issues are both theoretically and empirically at the core of the main dimensions of issue attitudes in West European politics (Kriesi et al., 2008; Rekker, 2015; Van der Brug and van Spanje, 2009) and were identified as core ideological correlates of leftright identification in the Netherlands (De Vries et al., 2013; Rekker, 2016). Furthermore, we compared the dynamics of political identity and issue attitudes both between low and highly educated voters and between adolescents and young adults. By doing so, we aimed to determine if the education gap in identityattitude consistency among adult voters originates from reciprocal adjustment during adolescence and early adulthood. Finally, we investigated how economic and cultural issues may play a differential role during specific life phases.

The results in this paper will reveal that youths primarily form an identity consistent with prior attitudes, although especially highly educated youths also adjust their attitudes to their identity. This manuscript will furthermore argue that early cultural attitudes 
establish an identity that may subsequently determine economic attitudes.

\subsection{Political identity in the Netherlands}

Voters' political identity exists of several facets, including partisanship (e.g., Democrat or Republican), ideological identity (e.g., liberal or conservative) and left-right identification (e.g., left or right). For example, it is common for voters to speak about Left and Right as a matter of who they are (e.g., 'I am leftist') and not merely of what they think (Schartau et al., 2011). Some theories argue that political identity is acquired early in life as an element of voters' general identity (e.g., Campbell et al., 1960). Indeed, an extensive body of literature from developmental psychology (e.g., Meeus et al., 2010) supports the idea (Erikson, 1950; Marcia, 1966) that forming a coherent self-identity is a core 'developmental task' during adolescence and early adulthood. For adolescents, their political identity may increasingly become part of who they are and whom they belong to in society. This political identity is likely to be adopted from parents (Jennings and Niemi, 1968; Jennings et al., 2009; Kroh and Selb, 2009) and accompanied by a strong emotional value (Green et al., 2002). Like other elements of identity (Meeus, 2011), political identity is believed to persist throughout the adult lifespan once it is established (Sears and Funk, 1999). Importantly, voters' political identity is also believed to be a core determinant of their voting behavior in every subsequent election (Campbell et al., 1960; Tillie and Fennema, 1998).

Although political identity consists of several components, the existing literature on its mutual relation with issue attitudes has focused mainly on partisanship (e.g., Campbell et al., 1960). Although partisanship is indeed a strong component of American voters' political identity (e.g., Green et al., 2002), this is not the case for Dutch voters who are characterized by exceptionally weak and unstable attachments with individual political parties (Bankert et al., 2016; LeDuc, 1981; Thomassen, 1976). Instead, research indicates that the dominant element of Dutch voters' political identity is their left-right identification (e.g., Van der Eijk and Niemöller, 1983; Rekker et al., 2014). The influential work of Inglehart and Klingemann (1976) argued that left-right identification partly captures voters' ideological identity, as well as their partisan identity. Comparative studies revealed that left-right identification in the Netherlands is strongly associated with both ideology and party preferences, but mostly with the latter (Freire, 2008; Knutsen, 1997; Van der Eijk et al., 2005; Westholm and Niemi, 1992). This implies that left-right identification largely captures the political identity of Dutch voters in general, and particularly their identification with political parties. This phenomenon is probably related to the fact that Dutch political parties are strongly aligned along a single left-right continuum (Adriaansen et al., 2005) and that most Dutch voters have a stable pattern of voting either for leftist or for rightist parties in every subsequent election (Van der Meer et al., 2015).

Although political identity consists of several facets, there is a strong theoretical and empirical interrelation between different components. For example, left-right identification in the Netherlands is characterized by the same properties (Converse, 1966; Thomassen, 1976) as partisanship in the United States: it can be measured as a single continuum, it makes it possible to characterize the political identity of large numbers of voters, it is highly stable throughout the lifespan (e.g., Rekker et al., 2014), it is strongly associated with (but distinct from) voting behavior (e.g., Tillie and Fennema, 1998), and it predominates the intergenerational transmission of political preferences (e.g., Westholm and Niemi, 1992). Because of these similarities, this study on left-right identification in the Netherlands derived its hypotheses partly from theoretical and empirical literature on partisanship in the United States.

\subsection{Political identity and issue attitudes}

Although there is undeniably a strong association between political identity and issue attitudes (e.g., Highton and Kam, 2011), the nature of this relation has been subject to considerable debate. Voters may adjust their issues attitudes to their political identity (i.e., identity influence) as well as vice versa (i.e., attitude influence). This psychological contradiction on the relation between identity and attitudes is related to a longstanding controversy on the nature and origins of partisanship in the United States. The Michigan model argues that partisanship is largely acquired early in life and subsequently serves as a stable basis for the acquisition of issue attitudes (e.g., Campbell et al., 1960; Converse, 1964). The Rochester school contrarily argues that issue attitudes are a cause of partisanship, more than a result (Achen, 2002; Downs, 1957; Fiorina, 1981; Franklin and Jackson, 1983; Key, 1966). If voters change their attitudes due to events or experiences, the Rochester model proposes that they will change their partisanship accordingly.

An extensive body of empirical literature has focused on unraveling if either identity influence or attitude influence best describes the causal relation between political identity and issue attitudes. Using cross-lagged models, panel studies have supported both mechanisms by revealing that political identity is predicted by prior issue attitudes as well as vice versa (Carsey and Layman, 2006; Evans and Neundorf, 2013; Franklin, 1984; Goren, 2005; Highton and Kam, 2011; Johnston, 2006). Although most of these studies focused on partisanship, some studies demonstrated a similar mutual relation between left-right identification and issue attitudes (Jæger, 2008; Pardos-Prado, 2011; Weber and Saris, 2014). All these studies were conducted on the major electoral panel studies that are available around the world (e.g., British Household Panel Study; National Election Study; Political Socialization Panel Study). By definition, these electoral studies only include respondents above or slightly under the legal voting age. As such, research on the mutual relation between political identity and issue attitudes has never focused on adolescence. This is an important limitation. Both political identity (Alwin and Krosnick, 1991; Schmitt-Beck et al., 2006; Sears and Funk, 1999) and issue attitudes (Krosnick and Alwin, 1989) are highly stable during adulthood. This means that studies on adults only investigate comparatively minor intra-individual changes and not the strong development that may occur during adolescence (Hooghe et al., 2013; Hooghe and Wilkenfeld, 2008; Jennings and Markus, 1984; Rekker et al., 2014, 2015; Sears and Valentino, 1997; Vollebergh et al., 2001). By including an adolescent sample, this study was the first to investigate if either political identity or issue attitudes are formed earlier in life and could therefore potentially serve as a basis for the other. While adult samples show how political identity and issue attitudes maintain each other after their initial formation, an adolescent sample allows us to truly test the influential idea that political identity is acquired early in life and subsequently serves as the basis for the development of issue attitudes (e.g., Campbell et al., 1960).

Important for understanding both mechanisms is the phenomenon that the consistency (i.e., association) between political identity and issue attitudes increases considerably during adolescence and early adulthood (Rekker et al., 2014). Research shows that many American early adolescents can already identify as Democrat or Republican (Easton and Dennis, 1969; Greenstein, 1965; Hess and Torney, 1967) and that most Dutch adolescents of this age can likewise identify as leftist or rightist (Rekker et al., 2014). However, political identity at this age may still be as 
rudimentary as 'left, us, the good guys' or 'Democrats, them, the bad guys' since early adolescents may not yet be able to connect their political identity to corresponding issue attitudes. As such, research shows that political identity is completely uncorrelated with issue attitudes among Dutch early adolescents (Rekker et al., 2014). However, this identity-attitude consistency was also found to increase tremendously during subsequent years (Beck and Jennings, 1991; Boonen et al., 2014; Markus, 1979; Niemi and Jennings, 1991; Sears and Valentino, 1997). For example, one study found that the explained variance of issue attitudes in left-right identification surged from $0.6 \%$ around age 13.5 to $19.2 \%$ around age 23 (Rekker et al., 2014).

But how do youths acquire this identity-attitude consistency? For example, it may be very common for a 13-year old to identify as rightist while at the same time supporting efforts to redistribute wealth. Would this adolescent adjust his/her rightist identification to match his/her leftist attitudes or vice versa? Based on the idea of identity influence, we may expect youths to use their political identity to acquire issue attitudes. For example, an adolescent with a rightist identification may seek to adopt attitudes that match this self-concept. For this purpose, the adolescent may rely on rightist parties as a reference of what these attitudes may be. Through this process, an adolescent with a rightist identification may gradually adopt corresponding issue attitudes from rightist parties. As such, we postulated our first hypothesis:

H1. Prior political identity will predict issue attitudes (i.e., identity influence).

Drawing from the principle of attitude influence, we may contrarily expect youths to use their issue attitudes to acquire their political identity. An adolescent may first form issue attitudes by learning about society, his/her values, and his/her interests. The adolescent may then start to figure out what parties best represent these views and start to identify with them. As such, an adolescent with leftist issue attitudes may eventually adopt a corresponding leftist identification. Our second hypothesis was therefore postulated:

H2. Prior issue attitudes will predict political identity (i.e., attitude influence).

Though both mechanisms are not mutually exclusive, they may not be equally strong. Studies on adult samples have typically found a stronger effect for identity influence than for attitude influence (Carsey and Layman, 2006; Goren, 2005; Layman and Carsey, 2002; Lenz, 2009). It seems theoretically plausible that this may also be the case for youths, since the Michigan model of partisanship emphasizes the importance of adolescence and early adulthood much more than the Rochester model. As such, our third hypothesis was as follows:

H3. The effect of prior political identity on issue attitudes (i.e., identity influence) will be stronger than the reversed effect of prior issue attitudes on political identity (i.e., attitude influence).

\subsection{The education gap in identity-attitude consistency}

Important for understanding both identity influence and attitude influence is the phenomenon that the resulting consistency between political identity and issue attitudes is stronger for some voters than for others (Carsey and Layman, 2006). A key correlate of this identity-attitude consistency is voters' educational level. Research shows that highly educated voters are more likely than low educated voters to combine their political identity with corresponding issue attitudes (Converse, 1964; Pardos-Prado, 2011;
Sears and Funk, 1999). Since political identity (e.g., Sears and Valentino, 1997), issue attitudes (e.g., Alwin and Krosnick, 1991), and the association between the two (e.g., Rekker et al., 2014) are all acquired during adolescence and early adulthood, it seems likely that the education gap in identity-attitude consistency can also be traced back to this life phase. This study was the first to investigate this possibility, leading to our fourth hypothesis:

H4. Highly educated voters will show a stronger age-related increase in identity-attitude consistency than low educated voters.

If low and highly educated youths indeed diverge with age in identity-attitude consistency, the question is why this divergence occurs. Based on the idea of identity influence, we may reason that highly educated youths could have a stronger tendency to develop issue attitudes based on their political identity. Highly educated youths may identify more strongly with political parties (Wolak, 2009) and consequently have a stronger tendency to adopt their views. Likewise, highly educated youths may acquire a more elaborate understanding of the issue attitudes that match their political identity. By engaging in activities like reading about politics, political discussions, or watching political events, a highly educated adolescent with a leftist identification may for example learn that this identity is typically accompanied by egalitarian views on redistribution. Low educated youths engage less in such activities (e.g., Quintelier, 2010). Supporting this account, research on adults found that a higher level of cognitive mobilization (e.g., knowledge about politics) is associated with a stronger level of identity influence (Carsey and Layman, 2006). As such, our fifth hypotheis was postulated as follows:

H5. The effect of prior political identity on issue attitudes will be stronger for highly educated voters.

Based on the idea of attitude influence, we may likewise reason that highly educated youths could have a greater capacity to develop a political identity based on their issue attitudes. With regard to partisanship, the Rochester model for example assigns more rationality and agency to voters than the Michigan model (e.g., Downs, 1957; Fiorina, 1981). As such, the mechanism of attitude influence also assumes a substantial effort from youths. For attitude influence to occur, youths first have to form an autonomous opinion on political issues without using their political identity as a reference. They then have to figure out what parties best represent their views. Both steps may require a substantial level of cognitive mobilization that is more often present among highly educated youths. By learning about the economy in school, a highly educated adolescent may for example develop conservative views about redistribution. By watching political debates or reading party manifestos, this adolescent may then start to identify with the rightist parties that represent these conservative views. Low educated youths again engage less in such activities (e.g., Quintelier, 2010). In line with this explanation, research on adults found that a higher level of cognitive mobilization is associated with a stronger level of attitude influence (Carsey and Layman, 2006). Our sixth hypothesis was therefore as follows:

H6. The effect of prior issue attitudes on political identity will be stronger for highly educated voters.

\subsection{Life phases and issues}

Since previous research on the dynamics of political identity and issue attitudes has focused on adult samples, a main aim of the present study was to determine if these dynamics are different for adolescents. According to the Michigan model of partisanship, identity 
influence is something that specifically occurs early in life (e.g., Campbell et al., 1960). The present study is the first to investigate if identity influence is indeed stronger during adolescence than during adulthood. Contrarily, the Rochester model of partisanship model argues that attitude influence can occur at any age (e.g., Fiorina, 1981). These two positions lead to the following hypothesis:

H7. The effect of prior political identity on issue attitudes, but not the effect of prior issue attitudes on political identity, will be stronger during adolescence than during early adulthood.

However, this is not the only difference between adolescence and adulthood that may be expected. Since political identity and issue attitudes are largely established during adulthood, crosslagged studies on adults essentially investigate how one established characteristic predicts changes in another established characteristic. The present study is fundamentally different in this regard, since political identity and issue attitudes are still in the process of development during adolescence (e.g., Jennings and Markus, 1984). In this context, a cross-lagged model on political identity and issue attitudes investigates the developmental order of both phenomena (Meeus, 2014): Does the development of political identity precede the development of issue attitudes or vice versa?

For this question, it seems important to make a distinction between different domains of issue attitudes. Ever since the 1920s, theory has emphasized the importance of early childhood for the development of cultural attitudes (e.g., Adorno et al., 1950; Levy and Killen, 2008; Quintana and McKown, 2008). Indeed, an extensive body of research indicates that attitudes on cultural issues like the multicultural society can already be observed during childhood (see Raabe and Beelmann, 2011 for a review) and already reach a substantial stability during adolescence (Hooghe et al., 2013; Rekker et al., 2015). This implies that the development of cultural attitudes may precede the development of political identity. If this is the case, childhood cultural attitudes may constitute a basis for the formation of political identity during adolescence. In other words, adolescence may be characterized by a strong potential for attitude influence from cultural issues. Hence, our eighth hypothesis was as follows:

H8. The effect of prior issue attitudes on political identity during adolescence will be stronger for attitudes on the multicultural society than for attitudes on economic redistribution.

Whereas core cultural attitudes are already acquired during childhood, economic attitudes do not develop until late adolescence and early adulthood (Rekker et al., 2015; Vandoninck et al., 2014). Voters may not acquire a strong opinion about economic issues until they progress in their educational and job careers (Rekker et al., 2015). This implies that economic attitudes may follow the development of political identity rather than precede it. If this is the case, adolescent political identity may constitute a basis for the formation of economic attitudes during early adulthood. Contrarily, the potential for identity influence on cultural issues may have weakened during early adulthood since these attitudes are already well established at this age (Rekker et al., 2015). Our ninth hypothesis was therefore postulated as follows:

H9. The effect of prior political identity on issue attitudes during early adulthood will be stronger for attitudes on the economic redistribution than for attitudes on the multicultural society.

\section{Method}

\subsection{Sample and context}

This study was conducted on the 'Utrecht Study of Adolescent Development (USAD) 1991-1997' ('t Hart et al., 1993). USAD is a multipurpose cohort-sequential longitudinal study that started in 1991 by interviewing 3392 Dutch youths between age 12 and 25 . Respondents were randomly drawn from an existing representative panel of 10.000 households. A comparison between USAD and Dutch population figures shows that the study can be considered nationally representative, but only for native Dutch youths since almost no immigrants participated ("t Hart et al., 1993). Of the respondents who participated in the first wave, 822 refused to continue participation in subsequent waves. Of the 2570 remaining respondents, 1302 were selected to participate in a second wave in 1994 and a third wave in 1997. This decrease in sample size was therefore mainly due to a deliberate resampling procedure and not due to attrition. Our cohort-sequential analyses (see a more detailed description below) required us to exclude 103 respondents who were over 24 at the first wave in order to make subsequent cohorts overlap in the model. This resulted in an active sample of 1199 respondents. Respondents' age was about evenly distributed. The sample consisted of $42 \%$ males and $58 \%$ females.

Regarding the context of this study, a parliamentary election was held in the Netherlands shortly before the second wave of the USAD study in 1994 . This election was characterized by an extraordinarily high volatility rate with $21.5 \%$ of parliamentary seats shifting between parties (Mair, 2008). Both economic redistribution and the multicultural society were important issues for Dutch voters during the 1990s (De Vries et al., 2013), though the breakthrough of anti-immigrant parties in the Netherlands took place some years later during the 2000s (Pellikaan et al., 2007).

\subsection{Measures}

\subsubsection{Political identity and issue attitudes}

As outlined in the introduction, political identity was operationalized using left-right identification. The item was phrased "Where would you place your own political views?" Respondents indicated their position on a left-right dimension ranging from 1 (left) to 10 (right). Issue attitudes on economic redistribution were measured using five items with a 5-point scale. An example of an item is "Differences between low and high incomes should be smaller." The items were adopted from Middendorp's (1978) 'Equality of Income, Status, and Possession' scale and adjusted for use among adolescents by Meeus (1988). The items were used as a scale that demonstrated good reliability properties in our sample: $\alpha=0.85$ at all three waves. Issue attitudes on the multicultural society were measured using four items with a 5-point scale. An example of an item is "Foreigners pose a threat to our culture." The items were adopted from Hagendoorn and Janssen (1983) and used as a scale that demonstrated good reliability properties in our sample, ranging from $\alpha=0.84$ to 0.87 across the three waves. Descriptive statistics and bivariate correlations between variables are listed in Table 1. A complete list of items is displayed in Appendix 1.

\subsubsection{Educational level}

Dutch secondary education was divided in four tracks during the 1990s, in which adolescents were tracked based on a test score and advice from teachers starting at age 12 . The first was a four-year lower vocational track (VBO), the second a four-year higher vocational track (MAVO), the third a five-year general track (HAVO), and the fourth a six-year pre-academic track (VWO). For parsimony, this study merged these four tracks into two levels: low level education (lower and higher vocational) and high level education (general and pre-academic). The resulting variable was distributed $57 \%$ low education and $43 \%$ high education. Respondents were assigned the highest educational level they were presently enrolled in or had already completed at the third wave. 
Table 1

Descriptive statistics and bivariate correlations (Pearson's r).

\begin{tabular}{|c|c|c|c|c|c|c|c|c|c|c|c|}
\hline Variable & 2 & 3 & 4 & 5 & 6 & 7 & 8 & 9 & 10 & M & SD \\
\hline 1. Political Identity W1 & $0.45^{* * *}$ & $0.43^{* * *}$ & $0.24^{* * *}$ & $0.25^{* * *}$ & $0.15^{* * *}$ & $0.12^{* * *}$ & $0.10^{* *}$ & $0.11^{* *}$ & 0.03 & 5.41 & 1.79 \\
\hline 2. Political Identity W2 & & $0.53^{* * *}$ & $0.17^{* * *}$ & $0.27^{* * *}$ & $0.20^{* * *}$ & $0.24^{* * *}$ & $0.28^{* * *}$ & $0.26^{* * *}$ & -0.04 & 5.23 & 1.69 \\
\hline 3. Political Identity W3 & & & $0.20^{* * *}$ & $0.25^{* * *}$ & $0.24^{* * *}$ & $0.18^{* * *}$ & $0.23^{* * *}$ & $0.24^{* * *}$ & -0.03 & 5.16 & 1.60 \\
\hline 4. Economic Redistribution W1 & & & & $0.51^{* * *}$ & $0.43^{* * *}$ & -0.02 & $-0.12^{* * *}$ & $-0.11^{* *}$ & $0.21^{* * *}$ & 4.34 & 1.70 \\
\hline 5. Economic Redistribution W2 & & & & & $0.50^{* * *}$ & 0.03 & 0.01 & 0.01 & $0.12^{* * *}$ & 4.53 & 1.60 \\
\hline 6. Economic Redistribution W3 & & & & & & 0.04 & 0.03 & 0.04 & $0.11^{* * *}$ & 4.43 & 1.55 \\
\hline 7. Multicultural Society W1 & & & & & & & $0.58^{* * *}$ & $0.54^{* * *}$ & $-0.27^{* * *}$ & 4.78 & 2.10 \\
\hline 8. Multicultural Society W2 & & & & & & & & $0.77^{* * *}$ & $-0.33^{* * *}$ & 4.89 & 1.95 \\
\hline 9. Multicultural Society W3 & & & & & & & & & $-0.33^{* * *}$ & 4.64 & 1.79 \\
\hline 10. Education $(0=$ Low; $1=$ High $)$ & & & & & & & & & & 0.43 & 0.49 \\
\hline
\end{tabular}

Note. ${ }^{*} \mathrm{p}<0.05 .{ }^{* *} \mathrm{p}<0.01 .{ }^{* * *} \mathrm{p}<0.001$.

\subsection{Strategy of analysis}

This study used Robust Maximum Likelihood (MLR) to estimate cross-lagged panel models (e.g., Finkel, 1995; Kline, 2011). In this type of models, variables are regressed on the same variable (i.e., stability paths) and other variables (i.e., cross-paths) at a prior time point. As such, it can be determined if one construct predicts relative changes in another construct. Though cross-lagged models are often used to determine reciprocal causality between two variables, they may primarily be viewed as models of developmental order when studying constructs across adolescence (Meeus, 2014). In this context, cross-lagged models indicate if the development of a certain trait precedes the development of another trait. This temporal precedence is a necessary, though not a sufficient, condition for causality in development. Due to the nature of our data, we specified our models in a cohort-sequential manner. For this purpose, we divided respondents in four cohorts based on their age at the first wave: 12 to 15 (mean: $13.5 ; N=321$ ), 15 to 18 (mean: $16.5 ; N=341$ ), 18 to 21 (mean: $19.5 ; N=262$ ), and 21 to 24 (mean: $22.5 ; N=275$ ).

The mean age of each cohort was used as a time-point in the cross-lagged models. At the second (three years later) and the third wave (six years later) cohorts aged to the next time-point. This allowed us to estimate effects from age 13.5 to 28.5 . For most estimates, we could use several cohorts simultaneously. For example, the effect from age 16.5 to 19.5 constitutes the effect from the second to the third wave for the youngest cohort and the effect from the first to the second wave for the next cohort.

For our model specification, we first added parameters to a baseline model in a stepwise manner (explained in more detail in the results section). In each step, we decided that a set of parameters could be added if a $\mathrm{Chi}^{2}$ difference test indicated a significant improvement in the correspondence between the predicted and the observed data. Due to the use of MLR, $\mathrm{Chi}^{2}$ difference test were corrected as proposed by Satorra and Bentler (2001). Because Chi ${ }^{2}$ difference tests have a tendency to favor less parsimonious models in larger samples (e.g., Bentler and Bonett, 1980), we additionally required an improvement in the models' RMSEA, AIC, and sample adjusted BIC before parameters were added (e.g., Raftery, 1995).

After the final model was determined, we tested our hypotheses by conducting Wald tests on the parameter estimates. To average estimates, we imposed equality constraints on sets of parameters. For example, identity influence was estimated as the average of all cross-lagged effects from left-right identification on issue attitudes regarding both economic redistribution and the multicultural society. To determine the role of educational level, we specified a multigroup model to distinguish between low and highly educated respondents. For comparisons between adolescence and early adulthood, adolescence was defined as the effects from age 13.5 to 16.5 and from age 16.5 to 19.5 whereas early adulthood was defined as all effects from age 19.5 onwards.

\subsection{Statistical assumptions}

\subsubsection{Age, period, and cohort effects}

This study aimed to investigate age differences in identity influence and attitude influence. Such age effects may be confounded by period effects if only within-individual variation is used, or by cohort effects if only between-individual variation is used. A strength of the present study's cohort-sequential design is that it combines both types of variation to disentangle age, period, and cohort effects (e.g., Delli Carpini, 1989; Neundorf and Niemi, 2014; Prinzie and Onghena, 2005). For this purpose, we tested if parameters could be constrained between cohorts. For example, an effect from the second to the third wave for the youngest cohort should be equal to the effect from the first to the second wave for the next cohort since both constitute the transition from age 13.5 to 16.5. If this is the case, we can be fairly certain that age effects were not biased by either period or cohort effects.

\subsubsection{Measurement comparability}

An assumption for comparing identity influence and attitude influence is that the measurements of political identity and issue attitudes are comparable. First, this implies that both constructs have a common metric. For this purpose, we scaled issue attitudes to the metric of left-right identification ranging from 1 to 10 . To further validate the comparability of unstandardized coefficients, we also estimated standardized coefficients for all parameters. Second, measurement comparability implies that the measurement error of political identity is roughly equal to that of issue attitudes. If one construct is more reliable than the other in a cross-lagged model, the cross-lagged effect of the more reliable construct on the less reliable construct can be overestimated. To test this assumption, we used a method proposed by Heise (1969) that distinguishes measurement error from true change in test-retest correlations. Though this procedure indicated differential reliabilities for left-right identification (0.51), attitudes on economic redistribution $(0.60)$, and attitudes on the multicultural society (0.74), these differences may indicate a genuine lack of attitudes at younger ages (which is of substantive interest) as well as an inability of the measure to reliably measure these attitudes (which would be a methodological confound). We therefore repeated this procedure with only respondents who were between age 21 and 25 at wave 1 . Results indicated that the Heise estimate was almost exactly equivalent for left-right identification (0.57), attitudes on economic redistribution (0.58), and attitudes on the multicultural society (0.59). As such, the assumption of equal reliability was satisfied.

Methods to incorporate measurement error in the model were unavailable for this study because they either require multiple indicators or the assumption that measurement error is equal across waves. Procedures that require multiple indicators (e.g., Bollen, 
1989) could not be used because left-right identification is a singleitem measure. Methods that require the assumption that measurement error is equal across waves (e.g., Wiley and Wiley, 1970; Green and Palmquist, 1990) could not be used because this assumption is implausible for an adolescent sample. During early adolescence, measurement error is likely to account for a larger proportion of the total variation in the observed scores than at older ages because the true scores on political identity and issue attitudes are less established. This study therefore modelled all constructs as observed variables, rather than as latent variables.

\subsection{Missing values}

The percentage of missing values averaged $8.6 \%$ across variables and waves, with a maximum of $18.8 \%$ for attitudes on economic redistribution at wave 1 . Full Information Maximum Likelihood (FIML) was used to estimate parameters based on all available data. Little's (1988) Missing Completely at Random (MCAR) test revealed a good $\mathrm{Chi}^{2} / \mathrm{df}$ ratio of 1.22 (Bollen, 1989), which indicates that the use of FIML was appropriate.

\section{Results}

\subsection{Model building}

To arrive at a model on which to test our hypotheses, we first followed a sequence of adding parameters to a baseline model. This baseline model featured only autoregressive stability paths for leftright identification and both issue attitudes. We first added concurrent associations at each wave between left-right identification and issue attitudes, which improved model fit $\left(\Delta \chi^{2}(24)=195.845\right.$, $\mathrm{p}<0.001, \Delta$ RMSEA $=-0.013, \Delta$ AIC $=-175, \Delta \mathrm{BIC}=-129)$. Second, we added concurrent associations at each wave between redistribution attitudes and multiculturalism attitudes. These parameters deteriorated the model fit and were therefore excluded from subsequent analyses $\left(\Delta \chi^{2}(12)=14.499, \mathrm{p}=0.270\right.$, $\Delta$ RMSEA $=+0.007, \Delta$ AIC $=+6, \Delta \mathrm{BIC}=+29)$. Third, we improved model fit by adding cross-lagged effects of prior left-right identification on issue attitudes and vice versa $\left(\Delta \chi^{2}(32)=133.787\right.$, $\mathrm{p}<0.001, \Delta$ RMSEA $=-0.002, \Delta$ AIC $=-83, \Delta \mathrm{BIC}=-44)$. Fourth, we improved model fit by adding residual covariances between scores of each variable at wave 1 and scores of the same construct at wave $3\left(\Delta \chi^{2}(12)=150.752, \mathrm{p}<0.001, \Delta\right.$ RMSEA $=-0.051, \Delta$ AIC $=-159$, $\Delta \mathrm{BIC}=-136)$. We finally constrained all stability paths and crosslagged effects across the four age cohorts as outlined in the method section $\left(\Delta \chi^{2}(21)=35.249, p=0.027, \Delta\right.$ RMSEA $=+0.000$, $\Delta \mathrm{AIC}=-3, \Delta \mathrm{BIC}=-43)$. The unchanged RMSEA and improved AIC and sample adjusted BIC revealed that this constraint did not deteriorate model fit. This indicates that age effects were not biased by either period or cohort effects. Consequently, we could constrain parameters across age cohorts to estimate a single effect for each age. This final model had a good fit (model $\chi^{2}(73)=122.192$, $\mathrm{p}<0.001, \mathrm{RMSEA}=0.047, \mathrm{CFI}=0.980$ ) according to RMSEA and CFI criteria (Hu and Bentler, 1999) and is depicted in Fig. 1.

\subsection{Political identity and issue attitudes}

To estimate an average effect of identity influence and attitude influence, we first constrained cross-lagged effects across ages and issues (model $\chi^{2}(91)=150.737, \mathrm{p}<0.001$, RMSEA $=0.047$, $\mathrm{CFI}=0.975)$ and then tested hypotheses using a $\Delta \chi^{2}$ obtained from Wald tests. All parameter estimates are displayed in Table 2. As expected (H1), prior left-right identification predicted issue attitudes $\left(\mathrm{B}=0.07, \Delta \chi^{2}(1)=22.921, \mathrm{p}<0.001\right)$. Also as hypothesized (H2), prior issue attitudes reversely predicted left-right identification $\left(B=0.11, \Delta \chi^{2}(1)=70.052, p<0.001\right)$. The effect of prior issue

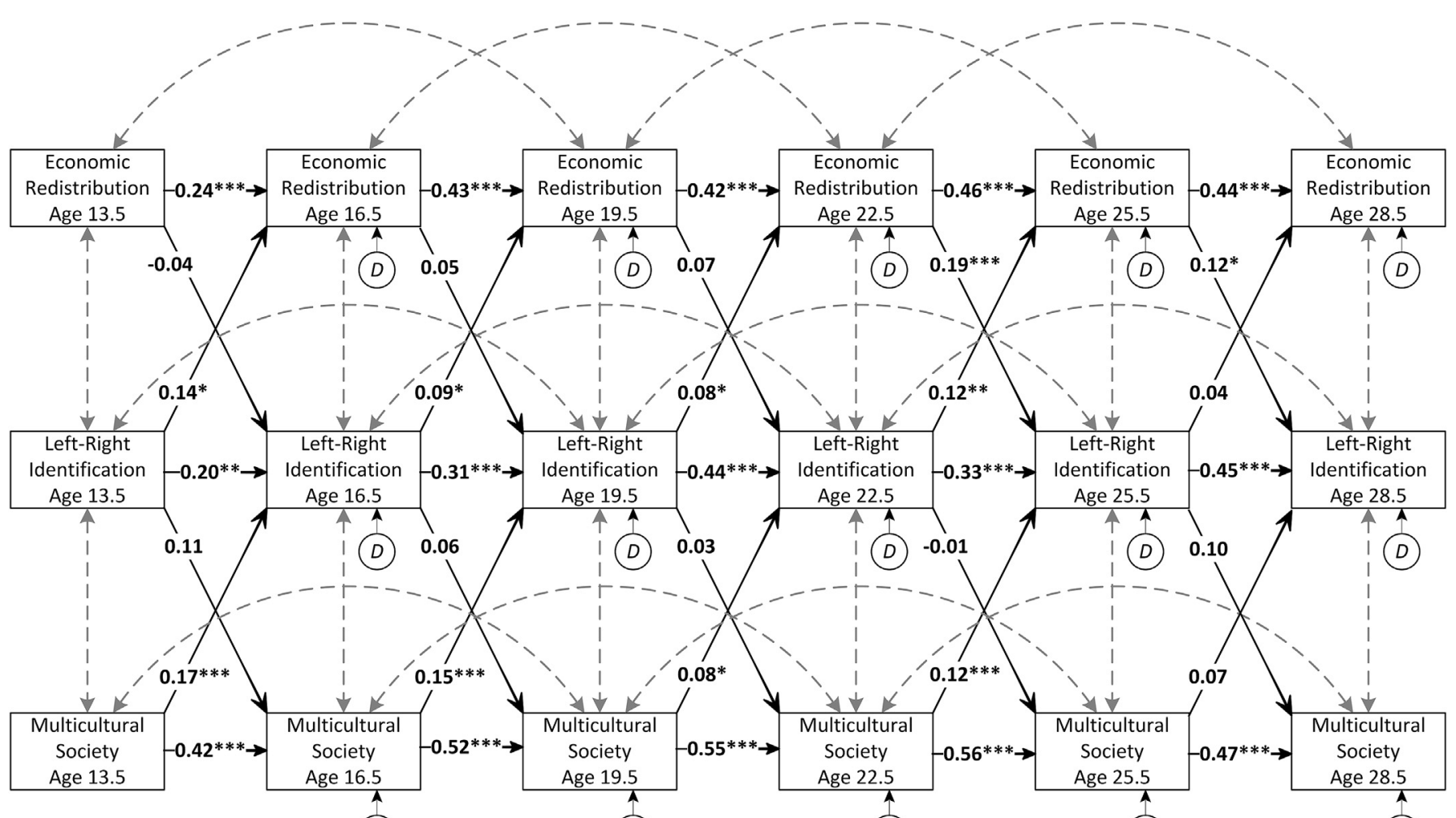

(D)

(D)

(D)

(D)

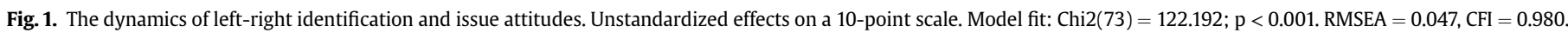


Table 2

Estimated effects by educational level, life phase, and issue.

\begin{tabular}{|c|c|c|c|c|c|c|c|}
\hline & \multicolumn{2}{|l|}{ Across Ages } & \multicolumn{2}{|l|}{ Adolescence } & \multicolumn{2}{|c|}{ Early Adulthood } & \multirow{2}{*}{$\frac{\text { Difference }}{\mathrm{B}}$} \\
\hline & $\mathrm{B}(\mathrm{SE})$ & Stand. & B (SE) & Stand. & B (SE) & Stand. & \\
\hline Identity influence & $0.07(0.01)^{* * *}$ & 0.07 & $0.09(0.03)^{* *}$ & 0.09 & $0.06(0.02)^{* * *}$ & 0.06 & -0.03 \\
\hline Attitude influence & $0.11(0.01)^{* * *}$ & 0.12 & $0.11(0.02)^{* * *}$ & 0.13 & $0.11(0.02)^{* * *}$ & 0.12 & -0.00 \\
\hline Difference & $+0.04^{*}$ & & +0.03 & & $+0.05^{*}$ & & \\
\hline \multicolumn{8}{|c|}{ Identity influence by educational level } \\
\hline Low education & $0.04(0.02)^{*}$ & 0.04 & $0.09(0.04)^{*}$ & 0.09 & $0.02(0.02)$ & 0.02 & -0.07 \\
\hline High education & $0.11(0.02)^{* * *}$ & 0.13 & $0.11(0.04)^{* *}$ & 0.12 & $0.12(0.02)^{* * *}$ & 0.13 & +0.00 \\
\hline Difference & $+0.08^{* *}$ & & +0.02 & & $+0.10^{* *}$ & & \\
\hline \multicolumn{8}{|c|}{ Attitude influence by educational level } \\
\hline Low education & $0.09(0.02)^{* * *}$ & 0.10 & $0.08(0.03)^{* *}$ & 0.10 & $0.09(0.02)^{* * *}$ & 0.10 & +0.01 \\
\hline High education & $0.13(0.02)^{* * *}$ & 0.13 & $0.12(0.04)^{* *}$ & 0.13 & $0.14(0.03)^{* * *}$ & 0.13 & +0.02 \\
\hline Difference & +0.04 & & +0.04 & & +0.05 & & \\
\hline \multicolumn{8}{|c|}{ Identity-attitude consistency by educational level } \\
\hline Low education & $2.3 \%(1.5)$ & 0.15 & $1.6 \%(2.0)$ & 0.13 & $5.0 \%(2.8)$ & 0.22 & $+3.4 \%$ \\
\hline High education & $18.8 \%(3.9)^{* * *}$ & 0.43 & $6.4 \%(3.9)$ & 0.25 & $31.6 \%(5.5)^{* * *}$ & 0.56 & $+25.2 \% * * *$ \\
\hline Difference & $+16.5 \% * * *$ & & $+4.8 \%$ & & $+26.6 \% * * *$ & & $+21.8 \% * *$ \\
\hline \multicolumn{8}{|l|}{ Identity influence by issue } \\
\hline Economic redistribution & $0.09(0.02)^{* * *}$ & 0.10 & $0.10(0.03)^{* *}$ & 0.11 & $0.09(0.02)^{* * *}$ & 0.10 & -0.01 \\
\hline Multicultural society & $0.04(0.02)^{*}$ & 0.04 & $0.07(0.04)$ & 0.06 & $0.03(0.02)$ & 0.03 & -0.04 \\
\hline Difference & $-0.05^{*}$ & & -0.03 & & $-0.06^{*}$ & & \\
\hline \multicolumn{8}{|l|}{ Attitude influence by issue } \\
\hline Economic redistribution & $0.10(0.02)^{* * *}$ & 0.10 & $0.03(0.04)$ & 0.03 & $0.13(0.02)^{* * *}$ & 0.13 & $+0.10^{*}$ \\
\hline Multicultural society & $0.12(0.02)^{* * *}$ & 0.14 & $0.16(0.03)^{* * * *}$ & 0.18 & $0.09(0.02)^{* * *}$ & 0.11 & $-0.07^{*}$ \\
\hline Difference & +0.01 & & $+0.13^{* *}$ & & -0.04 & & \\
\hline
\end{tabular}

Note. ${ }^{*} \mathrm{p}<0.05 .{ }^{* *} \mathrm{p}<0.01 .{ }^{* * *} \mathrm{p}<0.001$. Stand $=$ Standardized coefficient.

attitudes on left-right identification was stronger than the reversed effect of prior left-right identification on issue attitudes $(\Delta \mathrm{B}=0.04$, $\left.\Delta \chi^{2}(1)=6.104, \mathrm{p}=0.014\right)$. This finding contradicts our hypothesis (H3) that expected a difference in the opposite direction. In sum, we found support for both the mechanism of identity influence and attitude influence. Opposite to our expectation, the effect of prior issue attitudes on identity (i.e., attitude influence) was found to be stronger than the reverse effect of identity on attitudes (i.e., identity influence).

\subsection{The education gap in identity-attitude consistency}

To test our hypothesis that low and highly educated voters would diverge with age in identity-attitude consistency, we departed from our cross-lagged model to estimate what percentage of the variance in left-right identification at the first wave was explained by concurrent issue attitudes (displayed in Table 2). Using regular regression models with redistribution attitudes and multiculturalism attitudes as predictors, the explained variance in left-right identification was estimated for both low and highly educated voters during both adolescence (age 12 through 17) and early adulthood (age 18 through 25). Using the standard errors of these explained variances, we subsequently examined if this identity-attitude consistency differed between the four educationage groups (formula as proposed by Paternoster et al., 1998). Among low educated youths, the explained variance of issue attitudes in left-right identification showed only a non-significant increase from $1.6 \%$ during adolescence to $5.0 \%$ during early adulthood $\left(\Delta \mathrm{R}^{2}=3.4 \%, z=0.99, p=0.323\right)$. For highly educated youths, this identity-attitude consistency contrarily surged from $6.4 \%$ during adolescence to $31.6 \%$ during early adulthood $\left(\Delta \mathrm{R}^{2}=25.2 \%, z=3.74\right.$, $p<0.001$ ). Confirming our hypothesis ( $H 4)$, highly educated youths therefore showed a stronger increase in identity-attitude consistency than low educated youths $\left(\Delta \mathrm{R}^{2}=21.8 \%, z=2.88, p=0.004\right)$. This role of educational level is depicted in Fig. 2.

To examine what mechanism may explain this emerging education gap, we added educational level as an additional grouping variable (alongside cohort) to our cross-lagged model (model $\chi^{2}(182)=258.268, \mathrm{p}<0.001$, RMSEA $\left.=0.055, \mathrm{CFI}=0.966\right)$. As expected (H5), the effect of prior left-right identification on issue attitudes was stronger among highly educated youths than among low education youths $\left(\Delta \mathrm{B}=0.08, \Delta \chi^{2}(1)=7.701, \mathrm{p}=0.006\right)$. However, we found no support for our hypothesis (H6) that the effect of prior issue attitudes on left-right identification would similarly be stronger for highly educated youths $(\Delta \mathrm{B}=0.04$, $\left.\Delta \chi^{2}(1)=2.369, \mathrm{p}=0.124\right)$. Instead, we only found a non-significant difference in the expected direction. In sum, low and highly educated youths strongly diverged in identity-attitude consistency and this development may be explained by a heighted tendency of highly educated youths to bring their issue attitudes in line with their political identity.

\subsection{Life phases and issues}

To compare effects between adolescence and early adulthood, we modified parameter constraints on the cross-lagged model $\left(\right.$ model $\chi^{2}(89)=149.836, \mathrm{p}<0.001$, RMSEA $\left.=0.048, \mathrm{CFI}=0.975\right)$. Whereas we previously estimated average effects across life phases, we now estimated separate parameters for both adolescence and early adulthood (displayed in Table 2). Contrary to our hypothesis (H7), the effect of prior left-right identification on issue attitudes was not significantly stronger during adolescence than during early adulthood $\left(\Delta \mathrm{B}=0.03, \Delta \chi^{2}(1)=0.949, \mathrm{p}=0.330\right)$. Again, we found only a non-significant difference in the expected direction.

To investigate the differential effect of economic and cultural issues during different life phases, we again modified parameter constraints to estimate separate parameters for both redistribution attitudes and multiculturalism attitudes during both adolescence and early adulthood (model $\chi^{2}(85)=135.147, \mathrm{p}<0.001$, RMSEA $=0.044, C F I=0.979)$. As expected $(H 8)$, the effect of prior issue attitudes on left-right identification during adolescence was substantially stronger for multiculturalism attitudes than for redistribution attitudes $\left(\Delta \mathrm{B}=0.13, \Delta \chi^{2}(1)=8.654, \mathrm{p}=0.003\right)$. Further illustrating the importance of early cultural attitudes during adolescence, an exploratory analysis showed that the effect on left-right identification of prior multiculturalism attitudes was 
Identity-Attitude Consistency

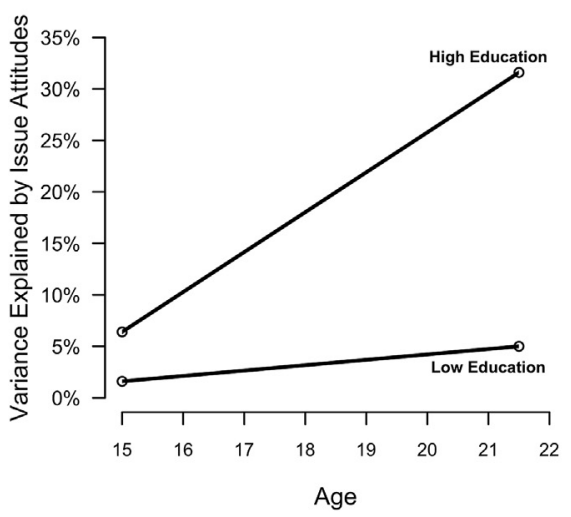

Identity Influence

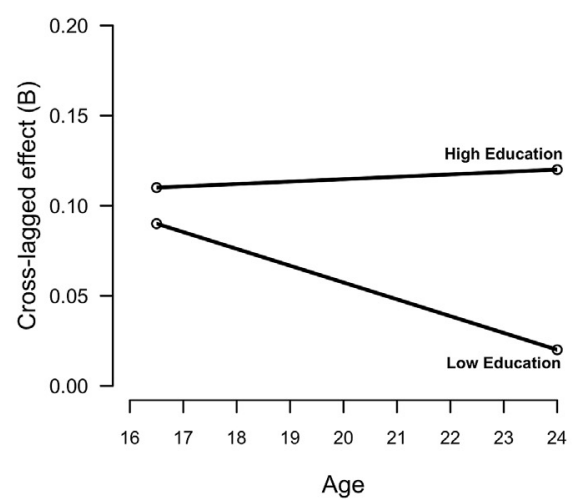

Attitude Influence

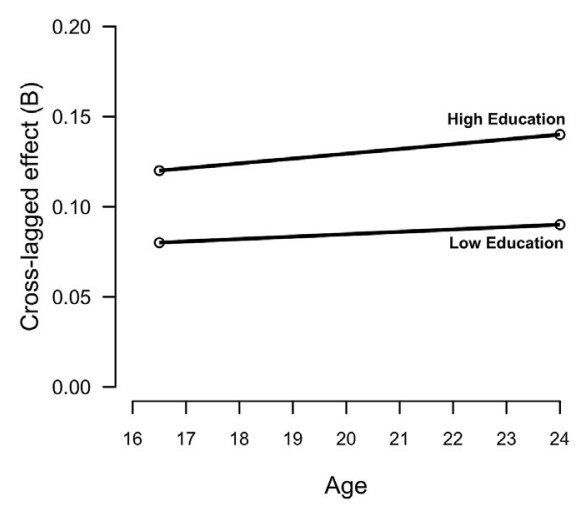

Fig. 2. Identity-attitude consistency, identity influence, and attitude influence by life phase and educational level.

stronger during adolescence than during early adulthood $\left(\Delta \mathrm{B}=0.07, \Delta \chi^{2}(1)=3.865, \mathrm{p}=0.049\right)$, whereas the effect of prior redistribution attitudes was reversely stronger during early adulthood than during adolescence $\left(\Delta \mathrm{B}=0.10, \Delta \chi^{2}(1)=5.893\right.$, $\mathrm{p}=0.015$ ). Also as hypothesized (H9), the effect of left-right identification on redistribution attitudes was stronger than on multiculturalism attitudes during early adulthood $(\Delta \mathrm{B}=0.06$, $\left.\Delta \chi^{2}(1)=3.898, \mathrm{p}=0.048\right)$ and consequently also when averaged across adolescence and early adulthood $\left(\Delta \mathrm{B}=0.05, \Delta \chi^{2}(1)=4.162\right.$, $\mathrm{p}=0.041)$. Further indicating a developmental order in which cultural attitudes precede left-right identification, an exploratory analysis revealed that multiculturalism attitudes predicted leftright identification more than vice versa $(\Delta \mathrm{B}=0.08$, $\left.\Delta \chi^{2}(1)=9.867, p=0.002\right)$. Contrarily, redistribution attitudes predicted left-right identification about equally as vice versa $\left(\Delta \mathrm{B}=0.01, \Delta \chi^{2}(1)=0.211, \mathrm{p}=0.646\right)$. Taken together, these results suggest a developmental order in which early issue attitudes on the multicultural society precede the acquisition of left-right identification during adolescence, which in turn predicts the development of attitudes on economic redistribution during early adulthood. This differential role of issues during adolescence and early adulthood is depicted in Fig. 3.

\section{Discussion}

This study examined how voters originally acquired their political identity early in life. Results indicated that youths form issue attitudes consistent with prior political identity (i.e., identity influence) as well as vice versa (i.e., attitude influence). Results furthermore revealed that attitude influence may be more pronounced during early life than identity influence. Furthermore, low and highly educated youths strongly diverged in identity-attitude consistency and this development could be explained by a heightened tendency of highly educated youths to bring their issue attitudes in line with their political identity. However, no support was found for the idea that highly educated youths are also more likely to reversely adjust their political identity to their issue attitudes. Comparing both mechanisms between life phases, we found no support for our hypothesis that identity influence would be stronger during adolescence than during early adulthood. However, differences between adolescence and early adulthood became apparent when a distinction was made between economic and cultural issues. As expected, early cultural attitudes were particularly important in predicting the formation of political identity during adolescence. Contrarily, political identity predicted the formation of economic attitudes more than the development of cultural attitudes during early adulthood.

\subsection{Political identity and issue attitudes}

Voters may adjust their issues attitudes to their political identity (i.e., identity influence) as well as vice versa (i.e., attitude influence). The primary aim of the present study was to, for the first time, investigate these mechanisms in a sample that includes adolescents. Findings provided support for the existence of both identity influence and attitude influence. In line with the idea of identity influence, this study found that prior political identity indeed predicts issue attitudes during both adolescence and early adulthood. Previous research indicated that many American early adolescents can already identify as Democrat or Republican (e.g., Easton and Dennis, 1969) and that most Dutch adolescents of this age can similarly identify as leftist or rightist (Rekker et al., 2014). Consistently, this study demonstrated that this early political identity predicts what issue attitudes adolescents will adopt in subsequent years.

However, findings also revealed that prior issue attitudes likewise predict political identity. Contrary to our expectations, prior issue attitudes in fact predicted political identity more than vice versa. This finding is remarkable in the light of classical models on partisanship, since the Michigan model emphasizes the importance of early life for identity influence, whereas the Rochester model claims that attitude influence may occur at any age. When viewed together, these findings on identity influence and attitude influence suggest that voters acquire their political identity and issue attitudes through a process of mutual adjustment. As such, this study provides an explanation for the phenomenon that identity-attitude consistency increases strongly during early life (e.g., Sears and Valentino, 1997).

\subsection{The education gap in identity-attitude consistency}

Since political identity, issue attitudes, and the association between the two are all acquired during adolescence (e.g., Alwin and Krosnick, 1991), we theorized that the education gap in identityattitude consistency can also be traced back to this life phase. Results strongly supported this hypothesis: Among highly educated youths, identity-attitude consistency surged from $6.4 \%$ during adolescence to $31.6 \%$ during early adulthood, whereas low educated youths only displayed a non-significant increase from $1.6 \%$ to $5.0 \%$.

Explaining this divergence, results furthermore indicated that highly educated youths have a stronger tendency to bring their issue attitudes in line with their political identity than low 
Identity Influence

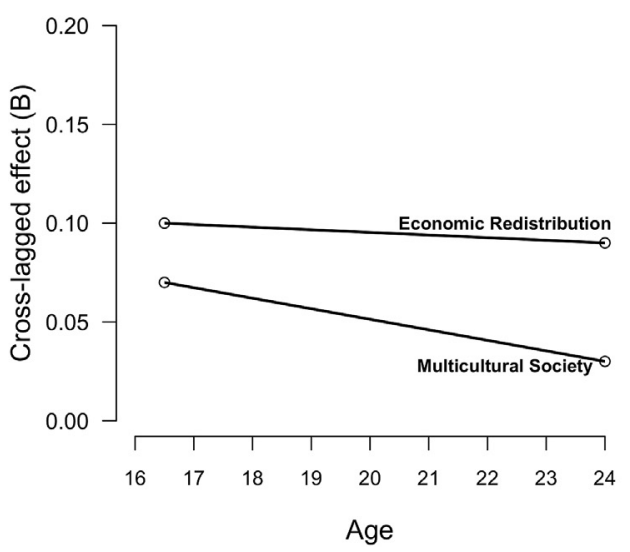

Attitude Influence

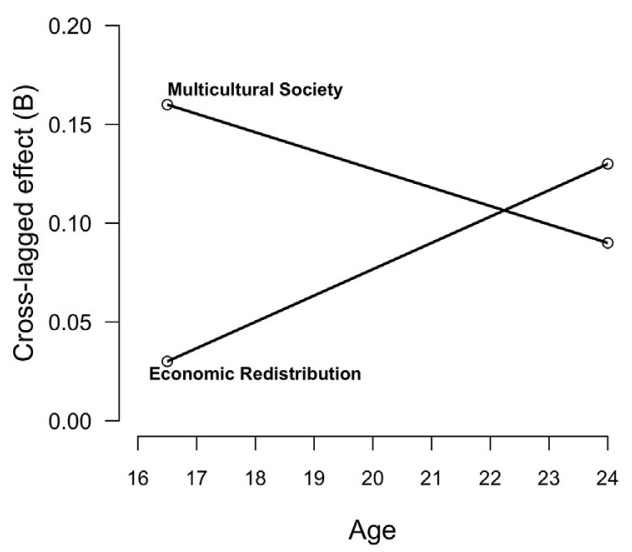

Fig. 3. Identity influence and attitude influence by life phase and issue. Appendix 1. Complete list of items and item-test correlations (calculated at wave 1).

educated youths. In other words, the higher identity-attitude consistency among highly educated voters may be explained by identity influence. This finding may be attributed to a stronger level of political identification among highly educated youths (Wolak, 2009) and by a more elaborate understanding of what issue attitudes match their identity. This interpretation is consistent with results from adult samples that a higher level of cognitive mobilization (e.g., knowledge about politics) is associated with a stronger level of identity influence (Carsey and Layman, 2006). Contrary to our expectation, we found no evidence that highly educated youths also have a stronger tendency to reversely bring their political identity in line with their issue attitudes. This is remarkable, since models of attitude influence traditionally expect more cognitive investment from voters than the models of identity influence (e.g., Downs, 1957).

The theoretical understanding of identity influence and attitude influence in general may be improved by studying what groups of voters display these mechanisms and under what circumstances (Carsey and Layman, 2006). In this regard, the finding that identity influence is stronger among highly educated voters indicates that it is an active process that requires a certain cognitive investment from voters. High-level education may therefore help adolescents to develop an understanding of political issues that is in line with their political identity.

\subsection{Life phases and issues}

By investigating the dynamics of political identity and issue attitudes between age 12 and 30, this study was in a unique position to compare these dynamics between adolescence and early adulthood. Despite the Michigan model's emphasis on early life, results failed to confirm that identity influence is stronger during adolescence than during early adulthood. However, this lack of differences between adolescence and early adulthood changed radically when a distinction was made between economic and cultural attitudes. Previous research demonstrated that attitudes on cultural issues like the multicultural society already develop during childhood (e.g., Raabe and Beelmann, 2011), whereas attitudes on economic issue like redistribution do not develop until late adolescence and early adulthood (e.g., Rekker et al., 2015). We therefore theorized that cultural issues may have a heightened potential to exercise attitude influence on the early formation of political identity. Results provided clear support for this hypothesis: Attitude influence from multiculturalism attitudes during adolescence was stronger than during early adulthood and also stronger than attitude influence from redistribution attitudes. Across adolescence and early adulthood, the relation between multiculturalism attitudes and political identity was characterized more by attitude influence than by identity influence. These findings underline the importance of childhood cultural attitudes for political development.

Also as expected, redistribution attitudes were contrarily more susceptible to identity influence than multiculturalism attitudes, particularly during early adulthood. The relation between political identity and redistribution attitudes was therefore characterized about equally by identity influence and attitude influence. Therefore, the mechanism of identity influence seems to describe the acquisition of economic attitudes better than that of cultural attitudes. Indeed, the overall finding that attitude influence was stronger than identity influence was mainly due to attitude influence from multiculturalism attitudes.

Taken together, results revealed a developmental order in which early issue attitudes on the multicultural society precede the acquisition of left-right identification during adolescence, which in turn predicts the development of attitudes on economic redistribution during early adulthood. By including an adolescent sample, this study was the first to detect this heightened attitude influence of early cultural orientations.

\subsection{Limitations}

Although this study could draw from highly suitable cohortsequential panel data, there are some limitations that warrant consideration. First, our cross-lagged models investigated the developmental order of political identity and issue attitudes (Meeus, 2014), whereas theoretical models make claims about the causal relation between both phenomena. Temporal precedence is a necessary, but not a sufficient, condition for causality in development. For example, it is possible that attitudes precede and predict political identity without actually causing it. Though we interpret our findings theoretically in causal terms, it is important to emphasize that cross-lagged models do not provide a definitive test of causality (Hamaker et al., 2015). Second, data were collected well before this article's time of writing. During the early 1990s, attitudes on both redistribution and the multicultural society were core correlates of political identity in the Netherlands and this was still the case nearly two decades later (De Vries et al., 2013; Rekker, 2016). It therefore seems plausible that the psychological 
mechanisms that were unraveled in this study can largely be generalized across time. However, it is possible that the role of multiculturalism attitudes in development has become even stronger, as these attitudes have become increasingly important during the 2000s, when anti-immigrant parties had their breakthrough in the Netherlands (De Vries et al., 2013).

\section{Conclusion}

By for the first time examining the dynamics of political identity and issue attitudes in adolescence, this study aimed to contribute to the theoretical understanding of the meaning and origins of political identity. Results revealed that political identity may be rooted in core cultural attitudes that voters acquire during childhood. If political identity was originally formed based on cultural attitudes, this tentatively suggests that it may still be rooted in such orientations for adult voters. In other words, voters may not change their political identity unless they change their core cultural attitudes. Following this reasoning, the strong persistence of cultural attitudes (e.g., Jennings and Markus, 1984; Henry and Sears, 2009) during adulthood may contribute to the strong stability of political identity (e.g., Sears and Funk, 1999).

\section{Acknowledgements}

This research was supported by a grant from the Coordinating Societal Change program of Utrecht University and by grants from the Netherlands Organisation for Scientific Research to USAD.

\section{Appendix 1. Complete list of items and item-test correlations (calculated at wave 1)}

\begin{tabular}{|c|c|}
\hline Item & $\begin{array}{l}\text { Item-test } \\
\text { correlation }\end{array}$ \\
\hline \multicolumn{2}{|l|}{ Left-Right Identification } \\
\hline “Where would you place your own political views?" & 1 \\
\hline \multicolumn{2}{|l|}{ Economic Redistribution } \\
\hline "Workers still have to fight for their rights" & 0.65 \\
\hline $\begin{array}{l}\text { "Differences in status between rich and poor should be } \\
\text { smaller" }\end{array}$ & 0.84 \\
\hline "Differences between classes should be smaller" & 0.80 \\
\hline $\begin{array}{l}\text { "Differences between low and high incomes should be } \\
\text { smaller" }\end{array}$ & 0.85 \\
\hline "Differences in possession should be smaller" & 0.83 \\
\hline \multicolumn{2}{|l|}{ Multicultural Society } \\
\hline “Unemployed Turks should definitely be expelled” & 0.86 \\
\hline "Our social provisions are not meant for foreigners" & 0.85 \\
\hline "Foreigners pose a threat to our culture" & 0.86 \\
\hline "Foreign employees steal our jobs" & 0.82 \\
\hline
\end{tabular}

\section{References}

Achen, C.H., 2002. Parental socialization and rational party identification. Polit. Behav. 24 (2), 151-170.

Adorno, T.W., Frenkel-Brunswik, E., Levinson, D., Sanford, N., 1950. The Authoritarian Personality. Norton, New York.

Adriaansen, M.J., Van der Brug, W., Van Spanje, J., 2005. De kiezer op drift? [The Voter at drift]. In: Brants, K., Van Praag, P. (Eds.), Politiek en media in verwarring - De verkiezingscampagnes in het lange jaar 2002 [The election campaigns in the long year 2002]. Het Spinhuis, Amsterdam.

Alwin, D.F., Krosnick, J.A., 1991. Aging, cohorts, and the stability of sociopolitical orientations over the life span. Am. J. Sociol. 97 (1), 169-195.

Bankert, A., Huddy, L., Martin Rosema, M., 2016. Measuring partisanship as a social identity in multi-party systems. Polit. Behav. 29 (1), 103-132.

Beck, P.A., Jennings, M.K., 1991. Family traditions, political periods, and the development of partisan orientation. J. Polit. 53 (3), 742-763.

Bentler, P.M., Bonett, D.G., 1980. Significance tests and goodness of fit in the analysis of covariance structures. Psychol. Bull. 88 (3), 588-606.

Bollen, K.A., 1989. Structural Equations with Latent Variables. Wiley, New York.

Boonen, J., Meeusen, C., Quintelier, E., 2014. The link between social attitudes and voting propensities: attitude-vote consistency among adolescents in Belgium. Elect. Stud. 36, 81-93. December.

Campbell, A., Converse, P.E., Miller, W.E., Stokes, D.E., 1960. The American Voter Wiley, New York.

Carsey, T.M., Layman, G.C., 2006. Changing sides or changing minds? Party identification and policy preferences in the American electorate. Am. J. Polit. Sci. 50 (2), 464-477.

Converse, P.E., 1964. The nature of belief systems in mass publics. In: Apter, D.E. (Ed.), Ideology and Discontent. Free Press, New York, pp. 206-261.

Converse, P.E., 1966. The concept of a normal vote. In: Campbell, A., Converse, P.E. Miller, W.E., Stokes, D.E. (Eds.), Elections and the Political Order. Wiley, New York.

Delli Carpini, M.X., 1989. Age and history: generations and sociopolitical change. In: Sigel, S.R. (Ed.), Political Learning in Adulthood. University of Chicago Press, Chicago, pp. $11-55$.

Downs, A., 1957. An Economic Theory of Democracy. Harper, New York.

Easton, D., Dennis, J., 1969. Children in the Political System. McGraw-Hill, New York.

Erikson, E.H., 1950. Childhood and Society. Norton, New York.

Evans, G., Neundorf, A., 2013. Core political values and the long term shaping of partisanship. In: Conference Paper at MPSA, Chicago IL.

Finkel, S., 1995. Causal Analysis with Panel Data. Sage, London.

Fiorina, M.P., 1981. Retrospective Voting in American National Elections. Yale University Press, New Haven, CT.

Franklin, C.H., 1984. Issue preferences, socialization, and the evolution of party identification. Am. J. Polit. Sci. 28 (3), 459-478.

Franklin, C.H., Jackson, J.E., 1983. The dynamics of party identification. Am. Polit. Sci. Rev. 77 (4), 957-973.

Freire, A., 2008. Party polarization and citizens' left-right orientations. Party Polit. 14 (2), 189-209.

Goren, P., 2005. Party identification and core political values. Am. J. Polit. Sci. 49 (4), $881-896$.

Green, D.P., Palmquist, B., 1990. Of artifacts and partisan instability. Am. J. Polit. Sci. 34 (3), 872-902.

Green, D.P., Palmquist, B., Schickler, E., 2002. Partisan Hearts and Minds: Political Parties and the Social Identities of Voters. Yale University Press, New Haven, CT/ London.

Greenstein, F.I., 1965. Children and Politics. Yale University Press, New Haven.

Hagendoorn, L., Janssen, J., 1983. Rechtsomkeer [Turn Right]. Ambo, Baarn.

Hamaker, E.L., Kuiper, R.M., Grasman, R.P.P.P., 2015. A critique of the cross-lagged panel model. Psychol. Methods 20 (1), 102-116.

t Hart, H., Meeus, W., Kox, W., 1993. Jongeren in Nederland: achtergronden en opzet van een nationaal survey [Youth in The Netherlands: background and design of a national survey]. In: Meeus, W., 't Hart, H. (Eds.), Jongeren in Nederland [Youth in the Netherlands]. Academische Uitgeverij Amersfoort, Amersfoort, pp. $11-30$.

Heise, D.R., 1969. Separating reliability and stability in test-retest correlation. Am. Sociol. Rev. 34 (1), 93-101.

Henry, P.J., Sears, D.O., 2009. The crystallization of contemporary racial prejudice across the lifespan. Polit. Psychol. 30 (4), 569-590.

Hess, R.D., Torney, J.V., 1967. The Development of Political Attitudes in Children. Aldine, Chicago.

Highton, B., Kam, C.D., 2011. The long-term dynamics of partisanship and issue orientations. J. Polit. 73 (1), 202-215.

Hooghe, M., Wilkenfeld, B., 2008. The stability of political attitudes and behaviors across adolescence and early adulthood: a comparison of survey data on adolescents and young adults in eight countries. J. Youth Adolesc. 37 (2), 155-167.

Hooghe, M., Meeusen, C., Quintelier, E., 2013. The impact of education and intergroup friendship on the development of ethnocentrism. A latent growth curve model analysis of a five-year panel study among Belgian late adolescents. Eur. Sociol. Rev. 29, 1109-1121.

Hu, L., Bentler, P.M., 1999. Cut-off criteria for fit indexes in covariance structure analysis: conventional criteria versus new alternatives. Struct. Equ. Model. 6 (1) $1-55$.

Inglehart, R., Klingemann, H., 1976. Party identification, ideological preference and the left-right dimension among western mass publics. In: Budge, I., Crewe, I. Farlie, D.J. (Eds.), Party Identification and beyond: Representations of Voting and Party Competition. John Wiley, London, pp. 243-273.

Jennings, M.K., Markus, G.B., 1984. Partisan orientations over the long haul: results from the three-wave political socialization panel study. Am. Polit. Sci. Rev. 78 (4), 1000-1018.

Jennings, M.K., Niemi, R.G., 1968. The transmission of political values from parent to child. Am. Polit. Sci. Rev. 62 (1), 169-184.

Jennings, M.K., Stoker, L., Bowers, J., 2009. Politics across generations: family transmission reexamined. J. Polit. 71 (03), 782-799.

Johnston, R., 2006. Party identification: unmoved mover or sum of preferences? Annu. Rev. Polit. Sci. 9, 329-351.

Jæger, M.M., 2008. Does left-right orientation have a causal effect on support for redistribution? Causal analysis with cross-sectional data using instrumental 
variables. Int. J. Public Opin. Res. 20 (3), 363-374.

Key, V.O., 1966. The Responsible Electorate. Harvard University Press, Cambridge, MA.

Kline, R.B., 2011. Principles and Practice of Structural Equation Modeling. Guilford Press, New York.

Knutsen, O., 1997. The partisan and the value-based component of left-right selfplacement: a comparative study. Int. Polit. Sci. Rev. 18 (2), 191-225.

Kriesi, H., Grande, E., Lachat, R., Dolezal, M., Bornschier, S., Frey, T., 2008. West European Politics in the Age of Globalization. Cambridge University Press, Cambridge.

Kroh, M., Selb, P., 2009. Inheritance and the dynamics of party identification. Polit Behav. 31 (4), 559-574.

Krosnick, J.A., Alwin, D.F., 1989. Aging and susceptibility to attitude change. J. Personality Soc. Psychol. 57 (3), 416-425.

Layman, G.C., Carsey, T.M., 2002. Party polarization and party structuring of policy attitudes: a comparison of three NES panel studies. Polit. Behav. 24 (3) $199-236$.

LeDuc, L., 1981. The dynamic properties of party identification: a four-nation comparison. Eur. J. Polit. Res. 9 (3), 257-268.

Lenz, G.S., 2009. Learning and opinion change, not priming: reconsidering the priming hypothesis. Am. J. Polit. Sci. 53 (4), 821-837.

Levy, S.R., Killen, M., 2008. Intergroup Attitudes and Relations in Childhood through Adulthood. Oxford University Press, Oxford.

Little, R.J.A., 1988. A test of missing completely at random for multivariate data with missing values. J. Am. Stat. Assoc. 83 (404), 747-770.

Mair, P., 2008. Electoral volatility and the Dutch party system: a comparative perspective. Acta Polit. 43 (2), 235-253.

Marcia, J.E., 1966. Development and validation of ego- identity status. J. Personality Soc. Psychol. 3 (5), 551-558.

Markus, G.B., 1979. The political environment and the dynamics of public attitudes: a panel study. Am. J. Polit. Sci. 23 (2), 338-359.

Meeus, W., 1988. Adolescent conservatism: a two-dimensional concept. In: Hazekamp, J., Meeus, W., te Poel, Y. (Eds.), European Contributions to Youth Research. Free University Press, Amsterdam, pp. 101-116.

Meeus, W., 2011. The study of adolescent identity formation 2000-2010: a review of longitudinal research. J. Res. Adolesc. 21 (1), 75-94.

Meeus, W., 2014. Adolescent development: processes and principles. In: Invited Lecture at 15th SRA Biennial Meeting, Austin Texas.

Meeus, W., Van De Schoot, R., Keijsers, L., Schwartz, S.J., Branje, S., 2010. On the progression and stability of adolescent identity formation: a five-wave longitudinal study in early-to middle and middle-to-late adolescence. Child. Dev. 81 (5), 1565-1581.

Middendorp, C.P., 1978. Progressiveness and Conservatism: the Fundamental Dimensions of Ideological Controversy and Their Relationship to Social Class. Mouton, The Hague.

Neundorf, A., Niemi, R.G., 2014. Beyond political socialization: new approaches to age, period, cohort analysis. Elect. Stud. 33, 1-6. March.

Niemi, R.G., Jennings, M.K., 1991. Issues and inheritance in the formation of party identification. Am. J. Polit. Sci. 35 (4), 970-988.

Pardos-Prado, S., 2011. Framing attitudes towards immigrants in Europe: when competition does not matter. J. Ethn. Migr. Stud. 37 (7), 999-1015.

Paternoster, R., Brame, R., Mazerolle, P., Piquero, A., 1998. Using the correct statistical test for the equality of regression coefficients. Criminology 36 (4) $859-866$.

Pellikaan, H., de Lange, S.L., Van der Meer, T., 2007. Fortuyn's legacy: party system change in The Netherlands. Comp. Eur. Polit. 5 (3), 282-302.

Prinzie, P., Onghena, P., 2005. Cohort sequential design. In: Everitt, B., Howell, D. (Eds.), Encyclopedia of Statistics in Behavioral Science, vol. 1. Wiley, New York, pp. 319-322.

Quintana, S.M., McKown, C., 2008. Handbook of Race, Racism, and the Developing Child. John Wiley \& Sons, Hoboken NJ.

Quintelier, E., 2010. The effect of schools on political participation: a multileve logistic analysis. Res. Pap. Educ. 25 (2), 137-154.

Raabe, T. Beelmann, A., 2011. Development of ethnic, racial, and national prejudice in childhood and adolescence: a multinational meta-analysis of age differences. Child. Dev. 82 (6), 1715-1737.

Raftery, A.E., 1995. Bayesian model selection in social research. Sociol. Methodol. 25, $111-164$.

Rekker, R., 2015. Social cleavages, democratic representation, and measurement models. In: Conference Paper at ECPR in Montreal, Canada.

Rekker, R., 2016. The lasting impact of adolescence on left-right identification: cohort replacement and intracohort change in associations with issue attitudes. Elect. Stud. 44, 120-131.

Rekker, R., Keijsers, L., Branje, S., Meeus, W., 2014. Partisanship formation in adolescence and early adulthood: adoption, persistence, and determinants. In: Conference Paper at 'Youth Politics and Society' in Leuven, Belgium.

Rekker, R., Keijsers, L., Branje, S., Meeus, W., 2015. Political attitudes in adolescence and emerging adulthood: developmental changes in mean level, polarization, rank-order stability, and correlates. J. Adolesc. 41, 136-147.

Satorra, A., Bentler, P.M., 2001. A scaled difference chi square test statistic for moment-structure analysis. Psychometrika 66 (4), 507-514.

Schartau, M., Berglund, S., Lagerspetz, M., Henningsen, B., 2011. Political Culture: Values and Identities in the Baltic Sea Region: Northern Dimensions - European Perspectives, vol. 8. BWV Verlag, Berlin.

Schmitt-Beck, R., Weick, S., Christoph, B., 2006. Shaky attachments: individual-level stability and change of partisanship among West German voters, 1984-2001. Eur. J. Polit. Res. 45 (4), 581-608.

Sears, D.O., Funk, C.L., 1999. Evidence of the long-term persistence of adults' political predispositions. J. Polit. 61 (01) 1-28.

Sears, D.O., Valentino, N.A., 1997. Politics matters: political events as catalysts for preadult socialization. Am. Polit. Sci. Rev. 91 (1), 45-65.

Thomassen, J., 1976. Party identification as a cross-cultural concept: its' meaning in The Netherlands. In: Budge, I., Crewe, I., Farlie, D. (Eds.), Party Identification and beyond. Wiley, London.

Tillie, J.N., Fennema, M., 1998. A rational choice for the extreme right. Acta Polit. 3 (33), 223-249.

Van der Brug, W., van Spanje, J., 2009. Immigration, Europe and the 'new' cultural dimension. Eur. J. Polit. Res. 48 (3), 309-334.

Van der Eijk, C. Niemöller, B., 1983. Electoral Change in the Netherlands: Empirical Results and Methods of Measurement. CT Press, Amsterdam.

Van der Eijk, C., Schmitt, H., Binder, T., 2005. Left-right orientations and party choice. In: Thomassen, J. (Ed.), The European Voter: a Comparative Study of Modern Democracies. Oxford University Press, Oxford, pp. 166-190.

Van der Meer, T.W.G., van Elsas, E., Lubbe, R., van der Brug, W., 2015. Are volatile voters erratic, whimsical or seriously picky? A panel study of 58 waves into the nature of electoral volatility (The Netherlands 2006-2010). Party Polit. 21 (1), $100-114$.

Vandoninck, J., Meeusen, C., Dejaeghere, Y., 2014. The effect of ethnic and civic nationalism and anti-immigrant prejudice on adolescents' support for welfare redistribution. In: Conference Paper at ECPR in Glasgow, United Kingdom.

Vollebergh, W.A.M., Iedema, J., Raaijmakers, W.A., 2001. Intergenerational transmission and the formation of cultural orientations in adolescence and young adulthood. J. Marriage Fam. 63 (4), 1185-1198.

De Vries, C.E., Hakhverdian, A., Lancee, B., 2013. The dynamics of voters' left/right identification: the role of economic and cultural attitudes. Polit. Sci. Res. Methods 1 (02), 223-238.

Weber, W., Saris, W.E., 2014. The relationship between issues and an individual's left-right orientation. Acta Polit. 43 (1), 193-213.

Westholm, A., Niemi, R.G., 1992. Political institutions and political socialization: a cross-national study. Comp. Polit. 25 (1), 25-41.

Wiley, D.E., Wiley, J.A., 1970. The estimation of measurement error in panel data. Am. Sociol. Rev. 35 (1), 112-117.

Wolak, J., 2009. Explaining change in party identification in adolescence. Elect. Stud. 28 (4), 573-583. 